See end of article for
authors' affiliations

Correspondence to

Dr J Lee Annest, Director Programming, Nationa

Center for Injury Prevention

and Control, Centers for

Disease Control and

Prevention, 4770 Buford

Hwy (MS-K59), Atlanta,

GA 3034 1-3724, USA;

lannest@cdc.gov

\section{Trends in BB/pellet gun injuries in children and teenagers in the United States, 1985-99}

\author{
M H Nguyen, J L Annest, J A Mercy, G W Ryan, L A Fingerhut
}

Injury Prevention 2002;8:185-191

\begin{abstract}
Objective: To characterize national trends in non-fatal BB/pellet gun related injury rates for persons aged 19 years or younger in relation to trends in non-fatal and fatal firearm related injury rates and discuss these trends in light of injury prevention and violence prevention efforts.

Setting: The National Electronic Injury Surveillance System (NEISS) includes approximately 100 hospitals with at least six beds that provide emergency services. These hospitals comprise a stratified probability sample of all US hospitals with emergency departments. The National Vital Statistics System (NVSS) is a complete census of all death certificates filed by states and is compiled annually.

Methods: National data on BB/pellet gun related injuries and injury rates were examined along with fatal and non-fatal firearm related injuries and injury rates. Non-fatal injury data for all BB/pellet gun related injury cases from 1985 through 1999, and firearm related injury cases from 1993 through 1999 were obtained from hospital emergency department records using the NEISS. Firearm related deaths from 1985 through 1999 were obtained from the NVSS.

Results: BB/pellet gun related injury rates increased from age 3 years to a peak at age 13 years and declined thereafter. In contrast, firearm related injury and death rates increased gradually until age 13 and then increased sharply until age 18 years. For persons aged 19 years and younger, BB/pellet gun related injury rates increased from the late 1980s until the early 1990s and then declined until 1999; these injury rates per 100000 population were 24.0 in 1988, 32.8 in 1992, and 18.3 in 1999. This trend was similar to those for fatal and non-fatal firearm related injury rates per 100000 which were 4.5 in 1985, 7.8 in 1993, and 4.3 in 1999 (fatal) and 38.6 in 1993 and 16.3 in 1999 (non-fatal). In 1999, an estimated 14313 (95\% confidence interval (CI) 12025 to 16601 ) cases with non-fatal $\mathrm{BB} /$ pellet gun injuries and an estimated 12748 (95\% Cl 7881-17 615) cases with non-fatal firearm related injuries among persons aged 19 years and younger were treated in US hospital emergency departments.

Conclusions: BB/pellet gun related and firearm related injury rates show similar declines since the early 1990s. These declines coincide with a growing number of prevention efforts aimed at reducing injuries to children from unsupervised access to guns and from youth violence. Evaluations at the state and local level are needed to determine true associations.
\end{abstract}

$\mathrm{B}$ $B$ and pellet gun related injuries represent an important public health concern in the US, especially for children and teenagers. A previous study reported that children and teenagers account for about $80 \%$ of all non-fatal $\mathrm{BB} /$ pellet gun related injuries. ${ }^{1}$ In the early 1990s, an estimated 23500 persons aged 19 years or younger were treated annually for non-fatal $\mathrm{BB} /$ pellet gun related injuries in US hospital emergency departments. ${ }^{2}$ Although a majority of these injuries in children and teenagers resulted from unintentional shootings, at least $10 \%$ of them were from interpersonal or self directed violence. ${ }^{2}$ This is in contrast to fatal and non-fatal firearm related injuries which are predominantly violence related. ${ }^{34}$

An estimated 3.2 million $\mathrm{BB} /$ pellet guns are sold in the US each year. Eighty per cent of these guns have muzzle velocities greater than 350 feet per second (fps) and 50\% have velocities between $500 \mathrm{fps}$ and $930 \mathrm{fps}^{2{ }^{2}}$ At close range, BBs and pellets fired from these air powered guns, especially those with velocities $>350 \mathrm{fps}$, can cause tissue damage similar to that inflicted by powder charged bullets fired from small caliber handguns. ${ }^{6}$ Numerous studies have documented the potentially severe or lethal nature of penetrating injuries from $\mathrm{BB} /$ pellet gunshots, especially those to the abdomen, chest, eye, and head of children. These studies indicate that unsupervised access to these guns by children is a major risk factor for injury. ${ }^{5-10}$ To reduce the risk of disability and death of patients inflicted with such wounds, some hospitals and doctors have modified their trauma care protocols to account for potentially severe, penetrating injuries from these compressed air powered guns. ${ }^{10-12}$

This study presents nationally representative data on trends in non-fatal BB/pellet gun related injury rates for persons aged 19 years and younger and compares these trends with national trends in fatal and non-fatal firearm related injury rates. National data are used to examine trends in gun related injury and death rates from 1985 through 1999, and to characterize these injuries by age, sex, race/ethnicity, intent of injury, and disposition at emergency department discharge. National data on $\mathrm{BB} /$ pellet gun related deaths were not included in our analysis because these deaths are coded in "other specified" categories and, therefore, cannot be uniquely identified using the International Classification of Diseases, 9th revision (ICD-9), external cause of injury coding system. ${ }^{13}$

\section{METHODS}

Data on non-fatal BB/pellet gun related injuries and non-fatal firearm related injuries were obtained using National Electronic Injury Surveillance System (NEISS) operated by the US

Abbreviations: $\mathrm{Cl}$, confidence interval; CPSC, Consumer Product Safety Commission; fps, feet per second; ICD-9, International Classification of Diseases, 9th revision; NEISS, National Electronic Injury Surveillance System; NVSS, National Vital Statistics System 
Table 1 Number of BB/pellet gun related injuries and firearm related injuries and deaths, and rates per 100000 population for persons aged 19 years and younger, by selected characteristics of the injured person, United States, 1993-99

\begin{tabular}{|c|c|c|c|c|c|c|c|c|c|}
\hline \multirow[b]{2}{*}{ Characteristics } & \multicolumn{3}{|c|}{ Non-fatal BB/pellet gun related injuries* } & \multicolumn{3}{|c|}{ Non-fatal firearm related injuries* } & \multicolumn{3}{|c|}{ Firearm related deaths } \\
\hline & No & $\begin{array}{l}\text { Mean } \\
\text { annual } \\
\text { No }\end{array}$ & Rate $(95 \% \mathrm{Cl})$ & No & $\begin{array}{l}\text { Mean } \\
\text { annual } \\
\text { No }\end{array}$ & Rate $(95 \% \mathrm{Cl})$ & No & $\begin{array}{l}\text { Mean } \\
\text { annual } \\
\text { No }\end{array}$ & Rate $(95 \% \mathrm{Cl})$ \\
\hline \multicolumn{10}{|l|}{ Age (in years) } \\
\hline $0-9$ & 26351 & 3764 & $9.7(7.9$ to 11.6$)$ & 4529 & 647 & $1.7(1.1$ to 2.2$)$ & 1387 & 198 & $0.5(0.49$ to 0.54$)$ \\
\hline $10-14$ & 64364 & 9195 & $48.4(41.6$ to 55.3$)$ & 16690 & 2384 & $12.6(8.9$ to 16.2$)$ & 3719 & 531 & 2.8 (2.71 to 2.89 ) \\
\hline $15-19$ & 31353 & 4479 & $24.0(20.6$ to 27.5$)$ & 121980 & 17426 & 93.5 (57.3 to 129.7$)$ & 27806 & 3972 & $21.3(21.07$ to 21.57$)$ \\
\hline \multicolumn{10}{|l|}{ Sext } \\
\hline Males & 105825 & 15118 & 38.7 (33.2 to 44.1$)$ & 126367 & 18052 & 46.2 (29.3 to 63.1$)$ & 28392 & 4056 & $10.4(10.26$ to 10.50$)$ \\
\hline Females & 16243 & 2320 & $6.2(5.2$ to 7.3$)$ & 16832 & 2405 & $6.5(4.1$ to 8.8$)$ & 4520 & 646 & $1.7(1.69$ to 1.79$)$ \\
\hline \multicolumn{10}{|l|}{ Race/ethnicity } \\
\hline White, non-Hispanic $\ddagger$ & 70474 & 10068 & 24.1 (19.8 to 28.4 ) & 27228 & 3890 & $8.3(6.2$ to 10.5$)$ & 11920 & 1703 & 3.4 (3.34 to 3.47 ) \\
\hline Black & 19614 & 2802 & $28.4(20.7$ to 36.1$)$ & 73348 & 10478 & 94.8 (43.7 to 146.0 ) & 13787 & 1970 & $16.7(16.39$ to 16.94$)$ \\
\hline Hispanic§ & 5450 & 779 & $9.0(4.2$ to 13.8$)$ & 27548 ** & 3935 ** & $40.5^{* *}(11.4 \text { to } 69.7)^{* *}$ & 5770 & 824 & $7.9(7.73$ to 8.14$)$ \\
\hline All other races/unknown $\mathbb{I}$ & 26530 & 3790 & - & 15076 & 2154 & 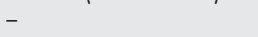 & 1435 & 205 & - \\
\hline Total & 122068 & 17438 & 22.9 (19.7 to 26.0 ) & 143199 & 20457 & $26.8(17.1$ to 36.6$)$ & 32912 & 4702 & $6.2(6.10$ to 6.23$)$ \\
\hline
\end{tabular}

* National estimates of non-fatal gunshot injuries treated in hospital emergency departments.

tThere were six cases of unknown sex for BB/pellet gun related injuries.

Excludes those who were of Hispanic origin.

$\S$ Excludes black Hispanic.

TIncludes non-Hispanic Asian/Pacific Islander, non-Hispanic American Indian/Alaska Native, and unknown race.

$* *$ Estimate may be unstable because the coefficient of variation was $>30 \%$.

Data sources: National Vital Statistics System, National Center for Health Statistics for deaths; Centers for Disease Control and Prevention's Firearm Injury

Surveillance Study for non-fatal injuries; US Census Bureau for population estimates.

Consumer Product Safety Commission (CPSC). Data from 1985 through 1992 on BB/pellet gun injuries were collected as part of CPSC's routine surveillance of consumer product related injuries using NEISS. Data from 1993 through 1999 on non-fatal $\mathrm{BB} /$ pellet gun related injuries and non-fatal firearm related injuries were collected through a "special study" using NEISS. ${ }^{14}$ This special study was implemented through an interagency agreement between the Centers for Disease Control and Prevention and CPSC to collect more detailed information about the circumstances of all gun related injury incidents. ${ }^{14}$

$\mathrm{A} \mathrm{BB} /$ pellet gun related injury was defined as a gunshot wound from a pistol or rifle that uses compressed air to fire a metal BB or pellet. These guns can operate through a spring or pump action mechanism or a carbon dioxide cartridge. ${ }^{15} \mathrm{~A}$ firearm related injury was defined as a gunshot wound from a pistol, revolver, or rifle that uses a powder charge to fire a projectile.

The NEISS is comprised of approximately 100 hospitals selected as a stratified probability sample of the approximately 5000 hospitals with emergency departments located throughout the US. ${ }^{16}{ }^{17}$ The system includes very large inner city hospitals with trauma centers, as well as urban, suburban, rural, and children's hospitals. Data obtained from these NEISS hospitals were weighted by the inverse of the probability of selection to provide national estimates of injuries treated in hospital emergency departments in the US and its territories. ${ }^{17}$ NEISS on-site personnel at each hospital were trained to identify all gun related cases treated in the emergency department by reviewing emergency department logs, trauma registries (when available), and emergency department charts. Based on information written in the medical record, on-site personnel classified gun related injuries by type of weapon (BB/pellet gun or firearm). For each BB/pellet gun related case from 1985 through 1992, coders abstracted information from the medical record on age and sex of the patient, nature of the injury, primary body part injured, disposition at discharge from the emergency department. For each special study gun related case treated from 1993 through 1999, coders abstracted those routine NEISS variables plus race/ethnicity of the patient, method of transport to the emergency department, type of firearm used, victim-offender relationship, intent of injury (for example, unintentional, suspected and confirmed assault, suspected and confirmed suicide attempt, law enforcement related), and other selected factors. A narrative taken verbatim from the medical record was also captured to provide more details about the injury circumstances. Further details of the system, abstraction methods, and evaluations of case ascertainment and completeness and accuracy of coding are provided elsewhere. ${ }^{18-20}$

In 1997, the sampling frame of NEISS was updated and a stratum was added for children's hospitals increasing the number of NEISS hospitals from 91 to $101 .{ }^{17}$ During an eight month overlap in 1997, gunshot cases were collected from both the old and new NEISS samples. Analysis of the weighted data indicated that differences in national estimates of non-fatal firearm related injuries based on these two samples were minimal (that is, $\leqslant 1 \%$ ). However, differences in national estimates of non-fatal $\mathrm{BB} /$ pellet gun related injuries were relatively high (that is, $\leqslant 15 \%$ ) and depended on age. To account for this, a SAS program developed by CPSC was used to calculate ratios for adjusting both firearm related and $\mathrm{BB} /$ pellet gun related injuries. These ratios were then applied to sample weights for NEISS cases before 1997 to ensure comparability of national estimates over time.

In cases before 1993, there was no way of distinguishing non-fatal BB/pellet gun related injuries associated with gunshot wounds from those induced by other causes (for example, lacerating or pinching finger on trigger after a fall). In the special study cases treated from 1993 through 1999, 4\% were determined to be non-gunshot wounds. Accordingly, rates calculated for the earlier years were adjusted downward by $4 \%$ to account for non-gunshot wound cases.

Race and ethnicity data for persons treated for non-fatal gun related injuries were obtained from NEISS hospital emergency department records. The majority of cases were reported as either white, black, Hispanic, Asian, or American Indian*. Those reported as black Hispanic were classified as black, and those reported as any other race and Hispanic were classified as Hispanic. ${ }^{3}$ Because of the small numbers of cases,

*Frequently, only one entry on the emergency department record is available for either race or identity, not for both. The classification scheme used in this study assumed that most white Hispanics, Asian/Pacific Islander Hispanics, or American Indian/Alaskan Native Hispanics, were likely to be recorded on the emergency department record as Hispanic and most black Hispanics were likely to be recorded as black. 


\begin{tabular}{|c|c|c|c|c|c|c|}
\hline \multirow[b]{2}{*}{ Characteristics } & \multicolumn{2}{|c|}{$\begin{array}{l}\text { Non-fatal BB/pellet gun } \\
\text { related injuries } \dagger\end{array}$} & \multicolumn{2}{|c|}{$\begin{array}{l}\text { Non-fatal firearm } \\
\text { related injuries } t\end{array}$} & \multicolumn{2}{|c|}{$\begin{array}{l}\text { Firearm related } \\
\text { deaths }\end{array}$} \\
\hline & No & $\begin{array}{l}\text { Mean (\%) } \\
\text { annual No }\end{array}$ & No & $\begin{array}{l}\text { Mean (\%) } \\
\text { annual No }\end{array}$ & No & $\begin{array}{l}\text { Mean (\%) } \\
\text { annual No }\end{array}$ \\
\hline \multicolumn{7}{|l|}{ Intent } \\
\hline Unintentional & 80345 & $11478(65.8)$ & 26633 & 3805 (18.6) & 2636 & $377(8.0)$ \\
\hline Assault $\ddagger$ & 11145 & $1592(9.1)$ & 92131 & $13162(64.3)$ & 20231 & $2890(61.5)$ \\
\hline Self inflicted & 201 ** & $29 * *(0.2)^{* *}$ & 4089 & $584(2.9)$ & 9365 & $1338(28.5)$ \\
\hline Undetermined & 30377 & $4340(24.9)$ & 20346 & 2907 (14.2) & 680 & $97(2.1)$ \\
\hline \multicolumn{7}{|l|}{ Disposition } \\
\hline Treated and released & 113917 & $16274(93.3)$ & 70014 & $10002(48.9)$ & - & - \\
\hline Treated and transferred & 3271 & $467(2.7)$ & 6707 & $958(4.7)$ & - & - \\
\hline Hospitalized & 4690 & $670(3.8)$ & 66170 & $9453(46.2)$ & - & - \\
\hline Observation/unknown & $190 * *$ & $27 * *(0.2)^{* *}$ & $308^{* *}$ & $44^{* *}(0.2)^{* *}$ & - & - \\
\hline \multicolumn{7}{|c|}{ Primary body part affected } \\
\hline Extremity & 65073 & $9296(53.3)$ & 76225 & $10889(53.2)$ & - & - \\
\hline Trunk & 14757 & 2108 (12.1) & 36901 & $5272(25.8)$ & - & - \\
\hline Face & 18784 & $2683(15.4)$ & 7504 & $1072(5.2)$ & - & - \\
\hline Head/neck & 14296 & $2042(11.7)$ & 13166 & $1881(9.2)$ & - & - \\
\hline Eye & 7258 & $1037(5.9)$ & 664 & $95(0.5)$ & - & - \\
\hline Other & 1901 & $272(1.6)$ & 8739 & $1248(6.1)$ & - & - \\
\hline Total & 122068 & $17438(100.0)$ & 143199 & $20457(100.0)$ & 32912 & $4702(100.0)$ \\
\hline
\end{tabular}

*Column percentages may not sum up to 100.0 due to rounding error.

†National estimates of non-fatal gunshot injuries treated in hospital emergency departments.

†lncludes injuries from legal intervention.

* Estimate may be unstable because sample size was $<20$ or the coefficient of variation was $>30 \%$.

Data sources: National Vital Statistics System, National Center for Health Statistics for deaths; Centers for

Disease Control and Prevention's Firearm Injury Surveillance Study for non-fatal injuries; US Census Bureau

for population estimates.

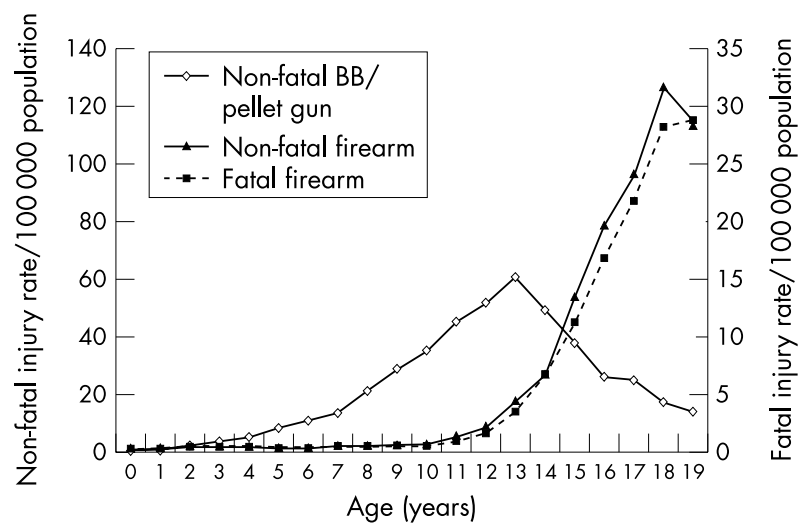

Figure 1 Non-fatal and fatal gun related injury rates per 100000 for persons aged 19 years or younger, by single year of age and weapon type, US, 1993-99.

non-Hispanic Asians/Pacific Islanders and non-Hispanic American Indians/Alaskan Natives were combined with other/unknown races.

Information about fatal firearm related injuries from 1985 through 1999 was obtained from the National Vital Statistics System (NVSS) of Center for Disease Control and Prevention's National Center for Health Statistics. The NVSS provides a complete enumeration of all deaths in the US. ${ }^{21}$ For this study, all firearm related deaths of residents of the US with an ICD-9 underlying cause of death code of E922.0-E922.9, E955.0E955.4, E965.0-E965.4, E985.0-E985.4, or E970 were included. ${ }^{13}$ Annual population estimates of the resident population, used to calculate injury and death rates per 100000 population, are from the US Census Bureau.

The 95\% confidence intervals (CI) around national estimates of numbers and rates were calculated using a direct variance estimation procedure that accounts for sample weights and the stratified sample design. ${ }^{16}$ Linear regression

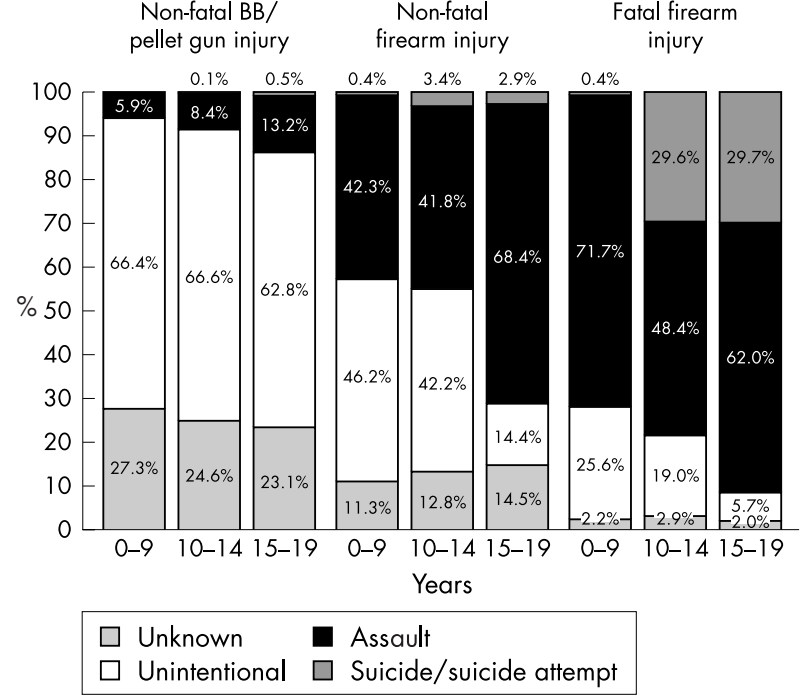

Figure 2 Non-fatal and fatal gun related injuries for persons aged 19 years or younger, by type of gun, age, and intent of injury, US, 1993-99.

was used to calculate the percentage decline in fatal and nonfatal gun related rates from the early 1990s through 1999. The 95\% CI calculated for these percentage declines also accounted for the sample weights and stratified sample design.

\section{RESULTS}

From 1993 through 1999, an estimated 122068 persons (95\% CI 105275 to 138861 ) aged 19 years or younger with non-fatal $\mathrm{BB} /$ pellet gun related injuries were treated in US hospital emergency departments. This represents an annual average of 17438 persons ranging from 22598 in 1993 to 14313 in 1999. These estimates were based on data obtained 


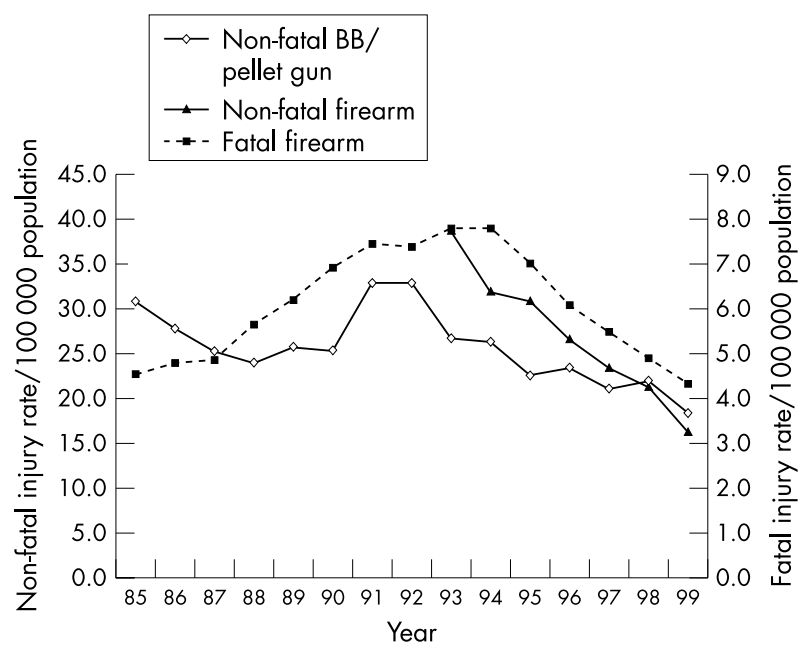

Figure 3 Non-fatal and fatal gun related injury rates per 100000 for persons aged 19 years or younger, by year and weapon type, US, 1985-99.

from 3076 sample persons using NEISS. The non-fatal $\mathrm{BB} /$ pellet gun related injury rate was highest for persons 10-14 years of age (table 1). Among this age group, the nonfatal $\mathrm{BB} /$ pellet gun related injury rate was 3.8 times the nonfatal firearm related injury rate and 17.3 times the fatal firearm related injury rate $(48.4 v 12.6$ and 2.8 per 100000$)$. Similar to firearm related injuries and deaths, non-fatal $\mathrm{BB} /$ pellet gun related injuries predominantly occurred among males (86.7\%; $95 \%$ CI $74.5 \%$ to $98.9 \%)$. The non-fatal $\mathrm{BB} /$ pellet gun related injury rate was similar for non-Hispanic whites and blacks, 24.1 and 28.4 per 100000 , in contrast to firearm related injury and death rates which were much higher among black than white persons, 94.8 and 8.3 per 100000 for injuries and 16.7 and 3.4 per 100000 for deaths. The BB/pellet gun related injury rate for Hispanics (9.0 per $100000)$ was about one third of the rate for non-Hispanic whites and blacks.

The age distributions differed for $\mathrm{BB} /$ pellet gun related injury rates and firearm related injury and death rates (fig 1). $\mathrm{BB} /$ pellet gun related injury rates increased sharply after age 7 years, peaked at age 13 years, and then declined thereafter. Firearm related injury and death rates increased gradually until age 13 years and then increased sharply until age 18 years.

Comparisons of non-fatal BB/pellet gun related injuries with firearm related injuries and deaths for selected characteristics also showed notable differences (table 2). While a majority of non-fatal $\mathrm{BB} /$ pellet gun related injuries were unintentional $(65.8 \%$; $95 \%$ CI $56.0 \%$ to $75.7 \%)$, firearm related injuries and deaths were mostly assaults (64.3\%; $95 \%$ CI $35.5 \%$ to $93.1 \%$ for injuries and $61.5 \%$; $95 \%$ CI $61.0 \%$ to $62.0 \%$ for deaths). Although the number of violence related injuries associated with $\mathrm{BB} /$ pellet guns, including assaults and suicide attempts, was relatively small, the percentage of violence related injuries increased with age (fig 2 ). This finding was consistent with an increase in the percentage of violence related firearm related injuries and deaths by age (fig 2).

When compared with non-fatal firearm related injuries (table 2), non-fatal BB/pellet gun related injuries were 12 times less likely to result in hospitalization $(3.8 \%$; $95 \%$ CI $2.7 \%$ to $5.0 \%$ compared with $46.2 \%$; $95 \%$ CI $23.1 \%$ to $69.3 \%)$. Compared with those who survived a firearm injury to the facial area and were treated in a hospital emergency department, non-fatal $\mathrm{BB} /$ pellet gun related injuries occurred three times more often to the face $(15.4 \%$; $95 \%$ CI $12.6 \%$ to $18.1 \%$ compared with $5.2 \%$; $95 \%$ CI $3.5 \%$ to $7.0 \%$ ) and almost 12 times more likely to involve an eye $(5.9 \%$; $95 \%$ CI $4.6 \%$ to $7.3 \%$ compared with $0.5 \%$; $95 \%$ CI $0.2 \%$ to $0.7 \%$ ).

Comparison of trends in $\mathrm{BB} /$ pellet gun related injury rates with firearm related injury and death rates showed similar patterns over the 12 year period from 1988 through 1999 (fig 3 ). BB/pellet gun injury rates increased from 1988 through 1992 and then declined thereafter; the predicted per cent change from 1992 through 1999 was $-38.8 \%$ (95\% CI $-48.0 \%$ to $-29.5 \%)$. Non-fatal firearm related injury rates declined steadily from 1993 through 1999; the predicted per cent change from 1993 through 1999 was $-55.0 \%$ (95\% CI $-60.1 \%$ to $-49.8 \%$ ). Firearm related death rates increased from 1985 through 1993 and then declined steadily after 1994; the predicted per cent change from 1994 through 1999 was $-45.2 \%$ ( $95 \%$ CI $-48.2 \%$ to $-42.1 \%)$.

\section{DISCUSSION}

$\mathrm{BB} /$ pellet gun related injuries and their potentially harmful and lethal effects have been well documented in the medical literature since the early 1980s. ${ }^{6}{ }^{12}{ }^{14-23} \mathrm{BB} /$ pellet gunshot wounds, particularly those inflicted at close range, can penetrate the abdomen, chest, head, and eye, and cause permanent damage and death. ${ }^{1024-26}$ Most of these injuries occurred in children and teenagers aged 19 years or younger. Based on NEISS data for the most current year available, 1999 , almost $76 \%$ of 18911 all persons with $\mathrm{BB} /$ pellet gun related injuries treated in US hospital emergency departments were 19 years of age or younger.

Trend analyses indicated that $\mathrm{BB} /$ pellet gun related injury rates for persons aged 19 years or younger declined

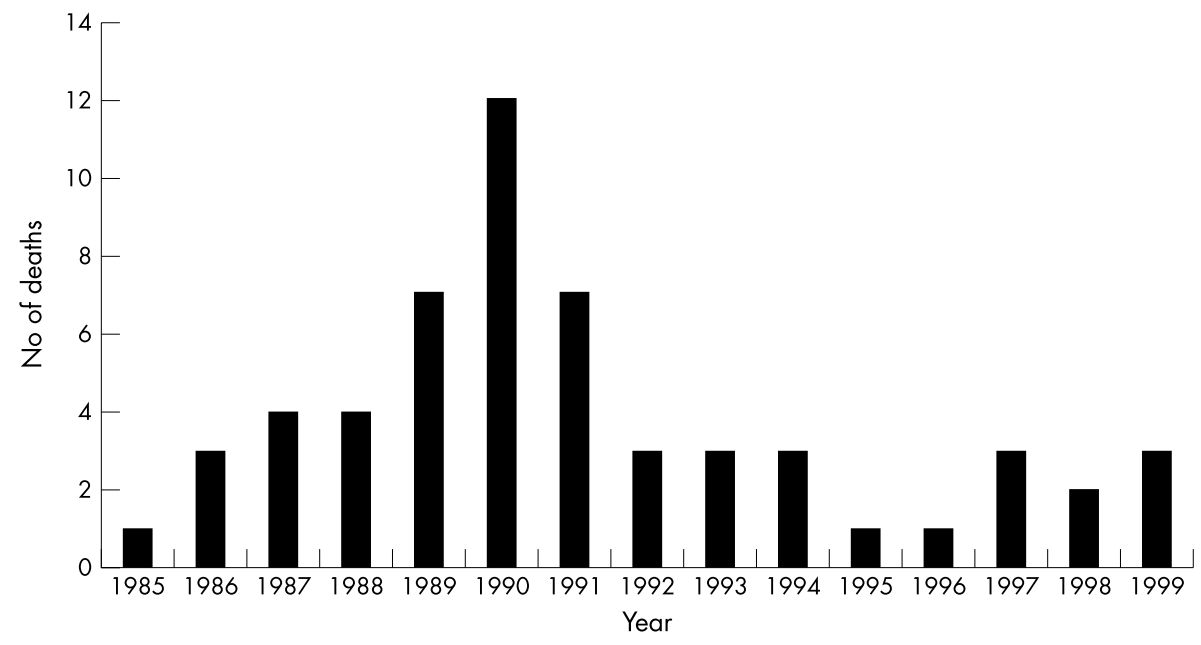

Figure 4 Number of BB/pellet gun related deaths for persons aged 17 years or younger, reported annually to CPCS, 1985-99. 
Table 3 State gun laws (2000) pertaining to possession/use and sales of BB/pellet guns

\begin{tabular}{|c|c|c|c|c|c|c|}
\hline State of residence & $\begin{array}{l}\text { BB/pellet gun } \\
\text { defined as firearm } \\
\text { or dangerous } \\
\text { weapon }\end{array}$ & $\begin{array}{l}\text { General } \\
\text { possession/use of } \\
\text { BB/pellet gun by } \\
\text { minors }\end{array}$ & $\begin{array}{l}\text { Selling of BB/pellet } \\
\text { guns to minors }\end{array}$ & $\begin{array}{l}\text { Possession/use of } \\
\text { BB/pellet guns in } \\
\text { and around schools }\end{array}$ & $\begin{array}{l}\text { Parent/guardian } \\
\text { responsible for } \\
\text { knowing illegal } \\
\text { possession of } \\
\text { firearm by minor }\end{array}$ & $\begin{array}{l}\text { Parent/guardian } \\
\text { responsible for } \\
\text { proper storage of } \\
\text { firearm }\end{array}$ \\
\hline AL & & & & $\mathrm{X}^{*}$ & & \\
\hline AK & & & & $X^{*}$ & & \\
\hline$A Z$ & & & & $X^{*}$ & $\mathrm{x}$ & \\
\hline AR & & & & $x \dagger$ & & \\
\hline CA & & $X(<18$ years) & $X(<18$ years) & $X^{*}$ & $x \ddagger$ & \\
\hline $\mathrm{CO}$ & & & & $\mathrm{X}^{*}$ & & \\
\hline CT & & & & $\mathrm{X}^{*}$ & $\mathrm{x}$ & $\mathrm{x}$ \\
\hline DE & & $X$ (<16 years) & $X$ (<16 years) & $\mathrm{X} \S$ & & \\
\hline DC & & & & & $\mathrm{x}$ & \\
\hline $\mathrm{FL}$ & & $X$ (<16 years) & & & $x$ & \\
\hline GA & & & & $X^{*}$ & $x$ & \\
\hline $\mathrm{HI}$ & & & & & & $\mathrm{x}$ \\
\hline ID & & $X *$ (<12 years) & $X^{*}$ (<18 years) & $X^{*}$ & & \\
\hline IL & $\mathrm{XI}$ & & & $\mathrm{X}^{\star *}$ & & $\mathrm{x}$ \\
\hline IN & & & & $X^{\star *}$ & & \\
\hline IA & & & & $X^{*}$ & & $x$ \\
\hline KS & & & & $X^{*}$ & & \\
\hline KY & & & & & $x$ & \\
\hline LA & & & & $\mathrm{X}^{*}$ & & \\
\hline ME & $\mathrm{x}$ & $X(<16$ years) & $X(<16$ years) & & $\mathrm{x}$ & \\
\hline MD & & & & $X^{*}$ & & \\
\hline MA & & $X(<18$ years $) \ddagger$ & $X(<18$ years) & $X^{*}$ & & $\mathrm{x}$ \\
\hline MI & $\mathrm{x}$ & $X(<18$ years $)$ & $X(<18$ years $)$ & $x \S$ & $\mathrm{x}$ & \\
\hline$M N$ & & $x(<14$ years $)$ & $X(<18$ years $)$ & $x \S$ & & \\
\hline MS & & & & $x \S$ & $\mathrm{x}$ & \\
\hline MO & & & & $X^{*}$ & & \\
\hline MT & & & & $X^{*}$ & $\mathrm{x}$ & \\
\hline NE & & & & $X^{* *}$ & & \\
\hline NV & $\mathrm{x}$ & & & $x \S$ & & \\
\hline $\mathrm{NH}$ & & $X(<18$ years) & $X$ (<18 years) & $x \S$ & & \\
\hline NJ & $\mathrm{x}$ & $x(<18$ years $)$ & $x(<18$ years $)$ & $x \S$ & $\mathrm{x}$ & $\mathrm{x}$ \\
\hline NM & & & & $X^{*}$ & & \\
\hline NY & & $X$ (<16 years) & $X$ (<16 years) & $X \S$ & & \\
\hline NC & $\mathrm{x} \dagger \dagger$ & $X(<12$ years) & $X(<12$ years) & $x \S$ & $\mathrm{x}$ & $\mathrm{x}$ \\
\hline ND & $x+\dagger$ & & & & & \\
\hline $\mathrm{OH}$ & & $X(<18$ years) $\ddagger$ & $X(<18$ years) $\ddagger$ & $X^{*}$ & $x \ddagger$ & $x \ddagger$ \\
\hline OK & $x+\dagger$ & $X(<18$ years) & $X(<18$ years $)$ & $X^{*}$ & $x$ & \\
\hline OR & & & & $X^{*}$ & & \\
\hline PA & & $X(<18$ years) & $X$ (<18 years) & & & \\
\hline RI & $x$ & $X(<18$ years $)$ & $X$ (<18 years $)$ & $X \S$ & $x$ & $x$ \\
\hline SC & & & & $\mathrm{X}^{*}$ & & \\
\hline SD & & & & $X \S$ & & \\
\hline TN & & & & $X^{*}$ & $\mathrm{x}$ & \\
\hline TX & & & & $X^{*}$ & $\mathrm{x}$ & $x$ \\
\hline UT & $x+\dagger$ & $X$ (<14 years) & & $X^{*}$ & $x$ & \\
\hline VT & & & $X$ (<16 years) & $X^{*}$ & & \\
\hline VA & & & & $\mathrm{X}^{*}$ & & \\
\hline WA & & & & $x \S$ & & \\
\hline WV & & & & $X^{* *}$ & & \\
\hline WI & $x+\dagger$ & $X(<18$ years) & & $\mathrm{X \S}$ & & \\
\hline WY & & & & & & \\
\hline Total No of states & 11 & 18 & 16 & 43 & 19 & 10 \\
\hline \multicolumn{7}{|c|}{ 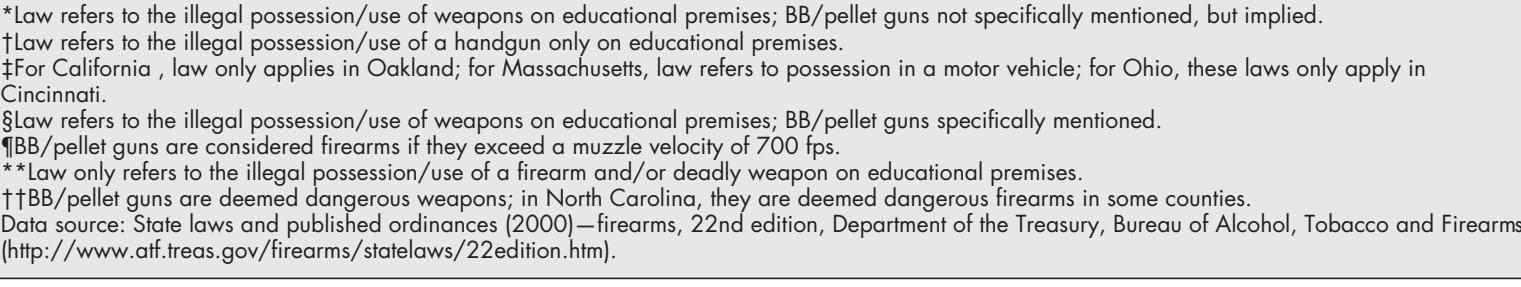 } \\
\hline
\end{tabular}

39\% from 1992 through 1999. In 1999, an estimated 14313 (95\% CI 12025 to 16601 ) children and teenagers with $\mathrm{BB} /$ pellet gun related injuries compared with an estimated 12748 (95\% CI 7881 to 17615 ) cases with non-fatal firearm related injuries were treated in US hospital emergency departments. NVSS data for 1999 indicated that 3385 persons 19 years of age or younger died from firearm related injuries, second only to motor vehicle traffic related injuries (7476 persons) as the leading cause of death in this age range in the US.
The ICD, the classification system used by the NVSS to code deaths, does not have external cause of injury codes to specifically identify $\mathrm{BB} /$ pellet gun related deaths. ${ }^{13}$ However, CPSC has an extensive consumer product related injury tracking system for use in identifying $\mathrm{BB} /$ pellet gun related deaths that occur each year. CPSC's system documented 57 deaths of persons aged 17 years or younger (or 3.8 deaths per year) from 1985 through 1999 (unpublished data from CPSC's In-Depth Investigation, Injury or Potential Injury Incident, and NEISS files). The highest number of deaths 
occurred in 1989, 1990, and 1991 (seven, 12, and seven deaths); the number of deaths ranged from one to four in other years (fig 4).

The decline in $\mathrm{BB} /$ pellet gun related injury rates was similar to the declines in firearm related injury rates and death rates among children and teenagers. This similarity is intriguing and could be potentially the result of legislative and educational efforts to prevent unsupervised access to guns by children. More research is needed to investigate the potential role of these efforts in explaining the decline in $\mathrm{BB} /$ pellet gun related injury rates. Most BB/pellet gun related injuries occurred among younger males, were unintentional shootings, and were either self inflicted or inflicted by a relative or friend. ${ }^{2}$ Public awareness and concern about this issue has increased since the early 1990s, as evidenced by increased legislation. In 1981, a survey by CPSC found that 12 states had laws that restricted possession or use of $\mathrm{BB} /$ pellet guns by minors and furnishing or selling these guns to children. ${ }^{27}$ According to a search using LexisNexis (Reed Elsevier, Inc, Dayton, Ohio), a database that provides full text access to state laws pertaining to firearms, that number increased to 14 states by 1994 and 28 states by $1996 .{ }^{15}$ Our research for the year 2000 found that 43 states currently have laws (table 3). ${ }^{28}$ Eleven states now have laws that define $\mathrm{BB} /$ pellet guns as either firearms or dangerous weapons. ${ }^{28}$ Nineteen states have enacted laws that hold parents or guardians legally responsible for injuries or deaths resulting from minors using their firearms and 10 states have laws requiring parents or guardians to protect minors by properly storing their firearms ${ }^{28}$ Safe storage laws intended to make firearms less accessible to children have been linked to a $23 \%$ reduction in unintentional shooting deaths of children aged 15 years or younger. ${ }^{29}$ Also, the number of unintentional firearm related injury deaths for children aged 19 years and younger in the US was relatively constant from 1985 through 1993 and then declined from 526 deaths in 1993 to 214 deaths in 1999. ${ }^{30}$

Another factor that might have contributed to the recent decline in $\mathrm{BB} /$ pellet gun related injury rates is the increase in prevention programs aimed at reducing gun violence among children and youth. Although BB/pellet gun related injuries were mostly unintentional, about $13 \%$ of $\mathrm{BB} /$ pellet gun related injuries among persons aged 15-19 years were assaults. Fatal and non-fatal firearm related injuries are predominantly violence related. Since the early 1990s firearm related injury and death rates have declined substantially in the US. ${ }^{3}$ Efforts supported by public health, criminal justice, and educational agencies and organizations may have contributed to the decline in $\mathrm{BB} /$ pellet gun related injuries, especially those associated with interpersonal violence. These efforts promote the adoption of youth violence prevention programs shown to be effective in reducing violent behavior and associated injuries and target parents, children, and teenagers. ${ }^{31}{ }^{32}$ In the year 2000, 63\% of all elementary and middle/junior high schools participated in programs to prevent bullying and $46.4 \%$ of all schools participated in a program in which family or community members serve as role models or mentor students, such as the Big Brothers/Big Sisters program. Most schools (96.1\%) also have a policy that prohibits student weapon possession or use. ${ }^{33}$ Prevention messages aimed specifically at reducing firearm related injuries among children have focused on increasing parent/guardian awareness of the increased risk of injury associated with unsupervised access to firearms, promoting safe gun storage and practices for gun owners and users, and educating policy makers about those at risk of injury.

Limitations of our data exist because our national estimates of non-fatal BB/pellet gun related injuries include only those that were treated in hospital emergency departments. $\mathrm{BB} /$ pellet gun related injuries that were not medically treated or were treated in outpatient clinics or doctors' offices were not included. We could not examine trends in BB/pellet gun related injuries treated in these outpatient settings because no

\section{Key points}

- Tracking BB/pellet gun and firearm related injury rates simultaneously can be an informative injury surveillance tool.

- For persons aged 19 years and younger, non-fatal $\mathrm{BB} /$ pellet gun related injuries have been declining along with fatal and non-fatal firearm related injuries from the early 1990s through 1999.

- Prevention efforts aimed at reducing unsupervised access to guns by children and reducing youth violence coincide with declines in $\mathrm{BB} /$ pellet gun related injury rates and firearm related injury and death rates for persons aged 19 years and younger in the US

- A carefully designed evaluation of the effectiveness of prevention efforts in reducing both $\mathrm{BB} /$ pellet gun and firearm related injuries at the state and local levels is warranted.

- Prevention messages should continue to remind parents and guardians that BB/pellet guns are not harmless toys. Not only can their children hurt themselves seriously from improper use of these guns, but they may also inflict injuries on others.

- Prevention efforts, including legislation and law enforcement, education, programs, and improved gun safety design, working collectively could potentially help to reduce the risk of gun related injuries and improve the safety of our children.

national data exist. NEISS provides nationally representative estimates, but does not accommodate state or local estimates. Additionally, NEISS is a probability sample of US hospitals and estimates are subject to sampling error. Nevertheless, the coefficients of variation for national estimates of $\mathrm{BB} /$ pellet gun related injuries have remained relatively small, approximately $7 \%$ overall for persons aged 19 years and younger, and have been stable over time. Also, adjustments were made for a NEISS sampling frame change that occurred in 1997 so that our trend analyses would be statistically valid. ${ }^{17}$ Trend analysis with or without these statistical adjustments lead to similar conclusions for this study.

\section{IMPLICATIONS FOR PREVENTION}

Prevention efforts have focused on informing gun owners that $\mathrm{BB} /$ pellet guns can be dangerous, even lethal, and need to be properly stored, locked and unloaded, so that children will not be tempted to play with them or use them without adult supervision. ${ }^{34}$ These prevention messages remind parents or guardians about their role in ensuring the safety of their children around guns. Parents or guardians should also be informed that injuries can occur to their children at a friend's home where a loaded, $\mathrm{BB} /$ pellet gun may be readily available. ${ }^{8}$ Parents need to take steps to ensure that their children, especially boys, are not exposed to $\mathrm{BB} /$ pellet guns in various places that they go and play. Boys have been found to choose handling a gun, if they find one, regardless of their parents' beliefs about their children's perceived interest in guns. ${ }^{35}$

Our study suggests that growing prevention efforts aimed at reducing unsupervised access to guns by children and reducing youth violence coincide with the decline in national $\mathrm{BB} /$ pellet gun related injury rates and firearm related injury and death rates in the US. A carefully designed evaluation at the state and local levels of prevention efforts aimed at reducing both $\mathrm{BB} /$ pellet gun related and firearm related injuries is warranted. These prevention efforts should be combined with other efforts, such as improving the design and safety features of guns; increasing the number of states with laws that restrict unsupervised access to powder and non-powder guns by minors; using stricter sentencing guidelines for crimes committed with guns ${ }^{36}$; and improving law enforcement practices. ${ }^{36}$ Together, these efforts could potentially help to reduce the risk of gun related injuries and improve the safety of our children. 


\section{ACKNOWLEDGEMENTS}

We would like to thank Dr Jennifer Madans for her helpful review and comments. We also thank Tom Schroeder, Art McDonald, Cathy Downs, and other CPSC staff for their diligence in collecting the NEISS data, Ms Patricia Holmgreen for preparation of analysis files, and Ms Karen Gotsch for help with data analysis and graphics presentations.

\section{Authors' affiliations}

M H Nguyen, J L Annest, J A Mercy, G W Ryan, National Center for Injury Prevention and Control, Centers for Disease Control and Prevention, Atlanta, Georgia

L A Fingerhut, National Center for Health Statistics, Centers for Disease Control and Prevention, Hyattsville, Maryland

\section{REFERENCES}

1 McNeill AM, Annest JL. The ongoing hazard of BB and pellet gun-related injuries in the United States. Ann Emerg Med 1995;26:187-94.

2 Centers for Disease Control and Prevention. BB and pellet gun-related injuries-United States, June 1992-May 1994. MMWR Morb Mortal Wkly Rep 1995;44(49):909-13.

3 Gotsch KE, Annest JL, Mercy JA, et al. Surveillance for fatal and nonfatal firearm-related injuries-United States, 1993-1998. CDC Surveillance Summaries, 13 April 2001. MMWR Morb Mortal Wkly Rep 2001;50(No SS-2): 1-36.

4 Sinaver N, Annest JL, Mercy JA. Unintentional, nonfatal firearm-related injuries. A preventable public health burden. JAMA 1996;275:1740-3.

5 Bratton SL, Dowd MD, Brogan TV, et al. Serious and fatal air gun injuries: more than meets the eye. Pediatrics 1997;100:609-12.

6 Harris W, Luterman A, Curreri PW. BB and pellet guns: toys or deadly weapons? J Trauma 1983;23:566-9.

7 DeCou JM, Abrams RS, Miller RS, et al. Life-threatening air rifle injuries to the heart in three boys. J Pediatr Surg 2000;35:785-7.

8 Enger C, Schein OD, Tielsch JM. Risk Factors for ocular injuries caused by air guns. Arch Ophthalmol 1996;1 14:469-74.

9 Friedman D, Hammond J, Cardone J, et al. The air gun: toy or weapon? South Med J 1996:89:475-8

10 DiGiulio GA, Kulick RM, Garcia VF. Penetrating abdominal air gun injuries: pitfalls in recognition and management. Ann Emerg Med 1995;26:224-8.

11 Bhattacharyya N, Bethel CA, Caniano DA, et al. The childhood air gun: serious injuries and surgical interventions. Pediatr Emerg Care 1998;14:188-90.

12 Pulido JS, Gupta S, Folk JC, et al. Perforating BB gun injuries of the globe. Ophthalmic Surg Lasers 1997;28:625-32.

13 World Health Organization. Manual of the international statistical classification of diseases and injuries, and causes of death. 9th revision. Geneva, Switzerland: World Health Organization, 1977.

14 Annest JL, Mercy JA, Gibson DR, et al. National estimates of nonfatal firearm-related injuries: beyond the tip of the iceberg. JAMA 1995;273:1749-54

15 Naude GP, Bongard FS. From deadly weapon to toy and back again: the danger of air rifles. J Trauma 1996:41:1039-43.

16 US Consumer Product Safety Commission (prepared by Schroeder T, Ault K). NEISS sample (design and implementation). National Electronic Injury Surveillance System sample design and implementation manual. Bethesda, MD: US Consumer Product Safety Commission, 2001.
17 US Consumer Product Safety Commission (prepared by Westat, Inc). Update of the NEISS sampling frame and sample. Bethesda, MD: US Consumer Product Safety Commission, 1996.

18 US Consumer Product Safety Commission (prepared by Schroeder T). NEISS coding manual. National Electronic Injury Surveillance System annual update. Bethesda, MD: US Consumer Product Safety Commission, 1999.

19 Davis Y, Annest JL, Powell KE, et al. Evaluation of the National Electronic Injury Surveillance System for use in monitoring nonfatal firearm injuries and obtaining national estimates. J Safety Res 1996;27:83-91.

20 US Consumer Product Safety Commission. Audit of the National Electronic Injury Surveillance System (NEISS) hospitals. Final system-wide analysis report to the US Consumer Product Safety Commission. Done under contract by Advanced Med Corp. Bethesda, MD: US Consumer Product Safety Commission, 2001.

21 Hoyert DL, Arias E, Smith BL, et al. Deaths: final data for 1999 National Vital Statistics Reports 2001;49(8):1-114.

22 Blocker $S$, Coln D, Chang JHT. Serious air rifle injuries in children. Pediatrics 1982:69:751-4.

23 DiMaio VJM, Copeland AR, Besant-Matthews PE, et al. Minima velocities necessary for perforation of skin by air gun pellets and bullets. J Forensic Sci 1982;27:894-8.

24 Nakamura DS, MCNamara JJ, Sanderson L, et al. Thoracic air gun injuries in children. Am J Surg 1983;146:39-42

25 Miner ME, Cabrera JA, Ford $E$, et al. Intracranial penetration due to $B B$ air rifle injuries. Neurosurgery 1986;19:952-4.

26 Brown GC, Tasman WS, Benson WE. BB-gun injuries to the eye. Ophthalmic Surgery 1985;16:505-8.

27 Christoffel JD, Christoffel K. Nonpowder firearm injuries: whose job is it to protect children? Am J Public Health 1987;77:735-8.

28 Bureau of Alcohol, Tobacco and Firearms. State laws and published ordinances-firearms. 22nd Ed. Washington, DC: Department of the Treasury, Bureau of Alcohol, Tobacco and Firearms, 2000 (http://www.atf.treas.gov/firearms/statelaws/22edition.htm).

29 Cummings $\mathbf{P}$, Grossman DC, Rivara FP, et al. State gun safe storage laws and child mortality due to firearms. JAMA 1997;278:1084-6.

30 Centers for Disease Control and Prevention. Web-based Injury Statistics Query and Reporting System (WISQARS ${ }^{\text {TM}}$ ) using data from the National Vital Statistics System. Atlanta, GA: National Center for Injury Prevention and Control, 2002 (http://www.cdc.gov/ncipc/wisqars).

31 US Department of Health and Human Services. Youth violence: a report of the surgeon general. Rockville, MD: US Department of Health and Human Services, Centers for Disease Control and Prevention, National Center for Injury Prevention and Control; Substance Abuse and Mental Health Services Administration, Center for Mental Health Services; and National Institutes of Health, National Institute of Mental Health, 2001: 1-176.

32 Thornton TN, Craft CA, Dahlberg LL, et al. Best practices of youth violence prevention: a sourcebook for community action. Atlanta, GA Centers for Disease Control and Prevention, National Center for Injury Prevention and Control, 2000: 1-207.

33 Small ML, Jones SE, Barrios LC, et al. School policy and environment: results from the School Health Policies and Programs Study 2000. J Sch Health 2001;71:325-34.

34 Damore DT, Ramundo ML, Hanna JP, et al. Parental attitudes toward BB and pellet guns. Clin Pediatr (Phila) 2000;39:281-4

35 Jackman GA, Farah MM, Kellermann AL, et al. Seeing is believing: what do boys do when they find a real gun? Pediatrics 2001; 107:1247-50.

36 Blumstein A, Wallman J, eds. Crime drop in America. New York: Cambridge University Press, 2000. 